used in the derived equations. In addition, with the seasonal redistribution of surface masses which gives rise to the forced motion in the variation of latitude, there is associated a seasonal variation of angular momentum relative to the solid earth, and this is responsible for an observable variation in the rate of rotation. Mr. Young shows that in the investigation of the effect of surface mass movements on the general rotation of the earth, the change in the length of the day may be treated independently of the variation of latitude. In addition, the seasonal variation of latitude can be described by the usual equations, but account may have to be taken of corrections for the angular momentum of the surface masses. He derives equations which are based on the assumption of axes of reference fixed in the solid earth, and hence fixed relative to an observer on the solid earth, which disposes of the doubt expressed by $\mathrm{Sir}$ Harold. It is claimed that the equations remain valid for secular changes in mass distribution over periods of decades ; but for periods of centuries some modifications in the equations may be necessary.

\section{Geological Museum, London}

THE Geological Museum in South Kensington has now been opened to the public for ten years-four before the Second World War and six years since. It was thus appropriate that in the February number of the Museums Journal Mr. A. J. Butler, assistant curator, should give a brief critical commentary based on experience gained during these years. Attendance at the Museum has risen progressively since the end of the War. Though the Museum is visited by specialized groups of the community, it is estimated that about a quarter of a million went for divers casual reasons. The success of the regional policy in exhibition is now assured, while the geological globe, the gemstones exhibit and the illuminated geological column are always centres of attraction. Mr. Butler is definitely of the opinion that the well-known dioramas have fully justified their initial outlay. He feels, however, that although the exhibits are arranged on a systematic plan, few visitors follow this but wander from one point to another according to the object which happens to hold their fancy.

\section{Index for 1921-50 of the Physical Review}

THE original intention of the American Physical Society was to publish a cumulative index to the Physical Review every tenth year; but this has never been realized. The first index covered the period from the first issue of the journal in 1893 to 1920 . In 1930 the world depression, and in 1940 the Second World War, prevented further publications. However, with the financial assistance of the Office of Naval Research and under the direction of Prof. J. W. Buchta, a cumulative index covering the thirty-year period 1921-50 has now been compiled. It is published in two volumes, an author index of 543 pages and a subject index of 498 pages. Prof. Buchta is the present editor of the Reviews of Modern Physics; but during the period covered by the index he was assistant editor of the Physical Review.

\section{Library Classifications}

IN a letter commenting upon Prof. Purchon's communication (see Nature, 172, 940; 1953) on library classification, which he thinks expresses the disappointment felt by others with the Library of Congress Classification, and the Universal Decimal
Classification, Mr. Faquir Chand, of the Department of Library Science, University of Delhi, directs attention to the Colon Classification invented by Prof. S. R. Ranganathan. Mr. Chand points out that during the past ten years Ranganathan and his co-workers in India and Great Britain have evolved several helpful concepts and techniques which have made such classification sufficiently resilient to accommodate new knowledge without disturbing the sequence among old knowledge. The fourth edition of Ranganathan's book "Colon Classification" was published by the Madras Library Association in 1952, and $\mathrm{Mr}$. Chand states that a new quarterly periodical, Annals of Library Science, will be published to communicate the findings of the Library Research Circle at Delhi, which is constantly engaged in giving effect to the new concepts and in improving the new techniques.

\section{Statistics and Personnel Management}

A PAPER on "Statistics and Personnel Management" was given by Prof. M. G. Kendall at the national conference of the Institute of Personnel Management in Harrogate during October last year, and it has now been published by the Institute (Occasional Paper No. 3; pp. 16 ; London, 1953 ; $3 s$.). It is an unexpectedly sprightly and general account of the subject, for Prof. Kendall has managed in the space of sixteen pages to make clear, if not to define, the essential nature of the statistical method in social applications, to state Pareto's Law and apply it illustratively to a question of wage-fixing, and to indicate ways in which statistics might, and perhaps should, be used in other managerial problems. The pamphlet forms useful reading for sixth forms of schools or first-year economics students.

\section{National Science Foundation : Grants}

THE award of a second group of grants during the fiscal year 1954 for the support of basic research and related matters has been announced by the National Science Foundation, Washington, D.C. The grants are a hundred in number and total about $1,045,000$ dollars, their purpose being for research in the biological and the physical sciences, and for the support. of studies and conferences on science, scientific information exchange, compilation of scientific personnel information, education in the sciences, and travel of American scientists to internationsl seientific meetings. The awards for research are for work in the following fields : astronomy, chemistry, developmental biology, earth sciences, environmental biology, engineering sciences, mathematical sciences, molecular biology, physics, psychobiology, regulatory biology and systematic biology. Tenure of the grants ranges from one to five years, with an average length of $2 \cdot 2$ years.

\section{Physical Soclety's Handbook of Scientific Instru-} ments and Apparatus

THE Physical Society's exhibition at the Imperial College of Science and Technology (Imperial Institute Road, London, S.W.7) is now a firmly established 'hardy annual' of London's scientific life, the recorded attendance last year being more than twenty thousand, and equally established and an essential requisite for all those who intend to visit the exhibition this year (to be held during April 8-13) is the Society's "Handbook of Scientific Instruments and Apparatus, 1954" (pp. 201 + pp. 76 advertisements ; from the Society, 1 Lowther Gardens, Prince 